\title{
OS GRAFISMOS URBANOS COMO MECANISMO DE BUSCA DO DIREITO À CIDADE SUSTENTÁVEL: UMA ANÁLISE SOB A ÓTICA DAS PRÁTICAS \\ SUSCEDIDAS NA CIDADE DE SANTA MARIA - RS
}

\author{
Bruna Hundertmarch ${ }^{1}$ \\ Cristiane Penning Pauli de Menezes ${ }^{2}$
}

\begin{abstract}
RESUMO: O presente artigo tem por escopo descortinar em que medida os grafismos urbanos podem ser analisados a partir do viés da manifestação cultural, configurando uma forma legítima de busca pelo acesso à cidade sustentável. Para tanto, utilizou-se como métodos de abordagem os métodos bibliográfico e documental. A guisa de conclusão obteve-se que ao investigar o propósito inicial dos grafismos, de dar voz a quem não está sendo ouvido, conclui-se que os espaços devem ser mais do que públicos, devem ser populares, com respeito a toda a diversidade própria do mundo globalizado e plural.
\end{abstract}

Palavras-chave: Cultura; direito à cidade; grafismo; patrimônio cultural; sustentabilidade.

\section{THE URBAN GRAPHICS AS A MECHANISM FOR SEARCHING THE RIGHT TO THE SUSTAINABLE CITY: AN ANALYSIS UNDER THE OPTICS OF THE PRACTICES SUSTAINED IN THE CITY OF SANTA MARIA - RS}

\begin{abstract}
The aim of this article is to discover the extent to which urban graphics can be analyzed from the bias of cultural manifestation, forming a legitimate way of searching for access to a sustainable city. For this, the bibliographic and documentary methods were used as methods of approach. As a conclusion, it was obtained that in investigating the initial purpose of the graphics, of giving voice to those who are not being heard, it concluded that the spaces must be more than public, they must be popular, with respect to all the proper diversity of the globalized and plural world.
\end{abstract}

\footnotetext{
1 Mestre em Direito pela Universidade Federal de Santa Maria - UFSM, no Programa de Pós-graduação em Direito, com ênfase em Direitos Emergentes na Sociedade Global, linha de Pesquisa Direitos da Sociobiodiversidade e Sustentabilidade. Pós-graduanda em Direito Empresarial e Advocacia Empresarial pela Faculdade Anhanguera UNIDERP. Graduada no Programa Especial de Graduação de Formação de Professores para a Educação Profissional da Universidade Federal de Santa Maria - UFSM (2015). E-mail: brunahundertmarch@ gmail.com.

2 Coordenadora do Núcleo de Estudos em Direito Internacional (NEDI) da Faculdade de Direito de Santa Maria (FADISMA). Professora de Direito da Faculdade de Direito de Santa Maria (FADISMA). Doutoranda no Programa de Pós-graduação em Processos e Manifestações Culturais - Universidade Feevale. Mestre (2016) pelo Programa de Pós-graduação em Direito da Universidade Federal de Santa Maria - UFSM, com ênfase em Direitos Emergentes na Sociedade Global, linha de Pesquisa Direitos da Sociobiodiversidade e Sustentabilidade. E-mail: cristiane.pauli@fadisma.com.br
} 
Keywords: Culture; Right to the City; Graphics; Cultural Heritage; Sustainability.

\section{INTRODUÇÃO}

A transmissão de valores e formas de agir e pensar consiste em uma prerrogativa única do ser humano, prática que dá ensejo ao surgimento de grupos e comunidades com diferentes características e perspectivas.

Nesse sentido, considerando que os grafismos urbanos estão cada vez mais presentes e integram a paisagem urbana, é fundamental que se promova uma discussão acerca deste fenômeno que se apresentada imbricado ao Direito à Cidade. Daí, retira-se o interesse social, uma vez que se vislumbra que o fenômeno dos grafismos urbanos são cada dia mais integrantes da paisagem urbana.

Nesse contexto, objetiva-se com o presente trabalho, investigar em que medida a prática dos grafismos urbanos (como representantes da cultura popular brasileira) podem serem consideradas constituintes do patrimônio cultural brasileiro e, mais, se a prática destes grafismos urbanos pode representar uma forma legítima de busca pelo Direito à Cidade.

A justificativa do presente trabalho se dá em vista a iminente necessidade de salvaguarda dos direitos culturais, juntamente da preocupação com a identificação de gargalos sociais das minorias e atual necessidade de democratização da cultura.

No que diz respeito à metodologia empregada, foram utilizados os métodos de abordagem bibliográfico e documental. A instrumentalização técnica desenvolveu-se por intermédio da produção de resenhas, resumos e análise de dois documentários. Além disso, procurou-se demonstrar a busca pelo Direito à Cidade por meio dos grafismos urbanos, a título de exemplificar o fenômeno vivenciado no âmbito das cidades.

Para tanto, foi realizado um levantamento fotográfico na cidade de Santa Maria, RS, o qual teve uma delimitação no tempo, uma vez que foi realizado no primeiro semestre de 2017, período em que se identificou um aumento gradativo das inserções gráficas no centro urbano da cidade e, portanto, torna-se fundamental demonstrar como tais manifestações apresentam-se. 


\title{
1. A CONCEITUAÇÃO DE CULTURA E A (IM)POSSIBILIDADE DE INCLUSÃO DOS GRAFISMOS NO ROL PROTECIONISTA
}

A cultura é a reunião das criações do homem e atua como fator indispensável na formação da sociedade e, por ser tão ampla, sua definição não é harmoniosa, propiciando que diversas áreas apontem conceitos distintos para esse instituto. De um lado, antropólogos preocupam-se com os fatores que tornam homogêneos os povos. De outra banda, sociólogos estudam movimentos que unem e afastam nações (CANCLINI, 2009, p. 14).

Cunha Filho reflete sobre o compartilhamento dos saberes entre os seres humanos:

\begin{abstract}
Um dos aspectos diferenciados do homem relativamente aos (outros) animais é a capacidade de raciocinar com profundidade e, mais que isso, multiplicar seu raciocínio, armazenando-o e difundindo-o aos seus semelhantes, que por sua vez repetem a operação, fato que provoca o crescimento exponencial das ideias, tanto no aspecto quantitativo como qualitativo. Para realizar este movimento, a humanidade utiliza-se de suportes que conservam, reproduzem e difundem as suas reflexões e o produto destas (CUNHA FILHO, 2004, p. $52)$.
\end{abstract}

A transmissão de valores e formas de agir e pensar consiste em uma prerrogativa única do ser humano, prática que dá ensejo ao surgimento de grupos e comunidades com diferentes características e perspectivas.

Cultura é tratada com frequência como resíduo, ou seja, um conjunto de sobras, resultado da separação de importantes aspectos da vida social. É aquilo que se extrai das atividades diretamente ligadas ao conhecimento no sentido amplo das áreas das ciências, da tecnologia, da educação, das comunicações, do sistema jurídico, do sistema político, às vezes da religião e dos esportes (SANTOS, 1986, p. 46).

O vocábulo cultura representa um conceito complexo e não uníssono. Gilles Lipovetsky e Jean Serroy (2011, p.07) aduzem que com a modernidade, que redesenha o mundo, constituiu-se uma nova forma de pensar a cultura. A cultura já não pode mais ser associada a uma estrutura de signos. Com nova roupagem, essa nova cultura, que nasce com o mundo moderno, transcende fronteiras e não é estanque.

Fica no caminho aquele conceito fechado, onde ficava nítida a evidente separação entre cultura erudita e cultura popular, "entre civilização das elites e barbárie do populacho" (LIPOVETSKY; SERROY, 2011, p. 08). 
Os grafismos urbanos podem ser definidos como intervenções gráficas que se dão no âmbito das cidades e, para os fins deste estudo, compreendem notadamente as práticas do pixo e do graffiti ${ }^{3}$. Tais expressões culturais constituem movimentos semelhantes, contudo, apresentam diferenças que merecem ser pontuadas.

Antes de avançar neste ponto, é necessário entender que o primeiro movimento se apresenta com inscrições literais, enquanto o segundo apresenta a inserção figuras. Em que pese, não se possa olvidar que diversos autores tratam de ambos como se fossem sinônimos e representassem simplesmente inserções gráficas no espaço urbano.

Para corroborar essa breve diferenciação, cumpre trazer o que disse Gitahy, que aduziu que "uma das diferenças entre o graffiti e a pixação é que o primeiro advém das artes plásticas e o segundo da escrita, ou seja, o graffiti privilegia a imagem; a pixação, a palavra e/ou a letra" (GITAHY, 1999, p.19).

Diversos autores debruçam-se na busca da conceituação ideal para estes movimentos, embora os conceitos não sejam uníssonos. Segundo Arce (1999, p. 132):

Os grupos de pichadores organizam-se reconhecendo um chefe que geralmente é o melhor para lutar. Não existe compromisso organizativo, isto é, usualmente se formam a partir de um grupo de amigos, definem um código de identificação e saem para popularizar seu nome. Posteriormente, novos amigos incorporamse e adotam o nome coletivo.

De forma semelhante, porém com inscrições que apresentam a inserção de figuras encontra-se o graffiti. Veja-se:

\begin{abstract}
O fenômeno do grafite, portanto, insere-se de maneira importante como parte da crise das identidades sociais. São jovens que reconstroem velhos referentes de identidade e que os utilizam para funcionar num novo contexto. Dessa maneira, participam da disputa cotidiana que estabelece a construção sociocultural dos espaços - produzidos e produtores de complexas redes de relações sociais que nos oferecem os discursos dos diferentes setores. (ARCE, 1999, p.138).
\end{abstract}

Não se pode tratar do pixo e do graffiti de forma superficial, pois sua especificidade exige um estudo aprofundado. Segundo Anita Rink (2013, p. 29-30), a expressão Graffiti surgiu com os romanos, que assim denominaram as mensagens de protestos em muros. Roma e outros sítios arqueológicos guardam em suas paredes registros sobre a vida cotidiana antiga em seus muros.

\footnotetext{
${ }^{3}$ O objetivo deste capítulo é trazer o conceito de pixação e graffiti de forma ampla sem adentrar nos aspectos culturais, legais e sua diferenciação quanto a forma de escrita. Pontos que serão tratados de forma pormenorizada no decorrer do trabalho.
} 


\section{OS GRAFISMOS URBANOS COMO MECANISMO DE BUSCA DO DIREITO À CIDADE SUSTENTÁVEL: UMA ANÁLISE SOB A ÓTICA DAS PRÁTICAS SUSCEDIDAS NA CIDADE \\ DE SANTA MARIA - RS}

As inserções nos muros e paredes possuem diversas vértices e intenções, apresentando-se como de cunho político, religioso, figurativo e outros tantos. Tal comparação permite dizer que a inserção de grafismos em paredes data de muito (RINK, 2013, p.29-30). Ainda nesse sentido, aborda Gitahy (1999, p.12) que:

[...] as manifestações mais antigas, com certeza, foram os desenhos feitos nas paredes das cavernas. Aquelas pinturas rupestres são os primeiros exemplos de graffiti que encontramos na história da arte. Elas representam animais, caçadores e símbolos, muitos dos quais, ainda hoje, são enigmas para os arqueólogos.

Naquela época, o graffiti era produzido com materiais disponíveis na natureza. Hodiernamente, em razão da virada cultural e tecnológica, o grafitti apresenta nova roupagem, e isso se dá pelo fato de que as manifestações culturais possuem ligação com o momento cultural e do período histórico no qual inserem-se.

A Pós-Modernidade, compreendida pelo período a partir de 1960, junto dos movimentos estudantis contribuiu muito na nova configuração do graffiti. No modernismo, diversos paradigmas foram quebrados e a literatura, a arte e arquitetura puseram-se a romper com os ideais iluministas, calcados na universalização da verdade, o que fez com que os artistas buscassem a destruição de antigos dogmas (RINK, 2013, p.31).

Posteriormente, a tinta látex ganhou força de produção junto da indústria automobilística, o que se deu a partir de 1950. A referida tinta spray passou a ser utilizada para diversos fins, inclusive para inserção de grafismos em paredes. Antes do látex, o piche era utilizado para intervenções estéticas, contudo, tal material, por ser de difícil remoção foi sempre associado a atos de vandalismo (RINK, 2013, p.33).

A pixação, por sua vez, pode ser conceituada como o ato de "escrever em muros e paredes; aplicar piche em; sujar com piche; falar mal. De acordo com esse último conceito, não há quem não tenha pichado uma vez na vida" (GITAHY, 1999, p. 20). A provocação trazida pelo autor é legítima, pois, ao fim e ao cabo, presta-se a reduzir em palavras exatamente o sentimento do pixo: revolta e busca por direitos.

Inegável, portanto, é a força da reunião de jovens, quando unidos por um ideal comum e, que a partir de movimentos como o graffiti e o pixo, manifestam-se na busca por reivindicações. Canclini (1997, p. 23) traz à baila um conceito parcial, latinoamericano, mas que se aplica de forma integral no contexto brasileiro: 
O grafite é para os mestiços da fronteira, para as tribos urbanas da Cidade do México, para grupos equivalentes de Buenos Aires ou Caracas, uma escritura territorial da cidade, destinada a afirmar a presença e até a posse sobre um bairro. As lutas pelo controle do espaço se estabelecem através de marcas próprias e modificações dos grafites de outros. Suas referências sexuais, políticas ou estéticas são maneiras de enunciar o modo de vida e de pensamento de um grupo que não dispõe de circuitos comerciais, políticos ou dos mass media para expressar se, mas que através do grafite afirma seu estilo. Seu traço manual, espontâneo, opõe-se estruturalmente às legendas políticas ou publicitárias "bem" pintadas ou impressas e desafia essas linguagens institucionalizadas quando as altera. O grafite afirma o território, mas desestrutura as coleções de bens materiais e simbólicos.

Percebe-se que Canclini (1997) traz um conceito amplo de graffiti, que, facilmente engloba o significado de pixo, posto que não é um conceito preocupado com a estética ou autorização, mas é intrinsicamente ligado a luta pelo espaço. Tal afirmação ganha maior referência quando o autor aduz que

O grafite é um meio sincrético e transcultural. Alguns fundem a palavra e a
imagem com um estilo descontínuo: a aglomeração de signos de diversos
autores em uma mesma parede é como uma versão artesanal do ritmo
fragmentado e heteróclito do videoclipe. Em outros se permutam as estratégias
da linguagem popular e da universitária, observa Armando Silva. Há também
"sínteses da topografia urbana" em muitos grafites recentes que eliminam a
fronteira entre o que se escrevia nos banheiros ou nos muros. É um modo
marginal desinstitucionalizado, efêmero, de assumir as novas reações entre o
privado e o público, entre a vida cotidiana e a política. (CANCLINI, 1997,
p.24).

Ou seja, quando aborda que existem diversos signos de diversos autores, com diversas ideias, está alargando o conceito e tratando-o como se fosse o conceito de grafismo urbano, de forma geral, tratando das inserções gráficas urbanas que aparecem nos muros e paredes das cidades, seja como forma de manifestação política, sexual ou que contemple outra conotação.

A cultura deve ser reinventada, uma vez que vários fatores interferem em sua definição. A cultura tradicional, quando necessário, deve abrir espaço às novas formas culturais, deve abrir espaço, portanto, às inovações culturais que nascem no seio da comunidade. Nesse sentido:

A luta entre a tradição e a inovação, que é o princípio de desenvolvimento interno da cultura das sociedades históricas, só pode prosseguir através da vitória permanente da inovação. Mas a inovação na cultura só é sustentada pelo movimento histórico total que, ao tomar consciência de sua totalidade, tende à superação de seus próprios pressupostos naturais e vai no sentido na supressão de toda separação. (DEBORD, 1997, p.120). 


\title{
OS GRAFISMOS URBANOS COMO MECANISMO DE BUSCA DO DIREITO À CIDADE SUSTENTÁVEL: UMA ANÁLISE SOB A ÓTICA DAS PRÁTICAS SUSCEDIDAS NA CIDADE

Diversos pesquisadores dedicam-se na busca da compreensão destas novas manifestações culturais, tendo em vista que se trata de um fenômeno complexo que contempla nuances de diversas áreas do conhecimento. Uma destas pesquisadoras é Marcia Tiburi (2013, p.40) que professa que o

\begin{abstract}
Mais adequado é falar na contra-consciência estética produzida por indivíduos e grupos, pois que não se trata de trabalhos ou "obras" que visam qualquer tipo de acordo com qualquer consideração que venha do campo das artes e seus cenários de consciências filosóficas pré-estabelecidas. Em termos teóricos, esta prática é também um questionamento sobre o fim da arte, incluso o fim de sua história, mas também o fim da teoria da arte, bem como o fim da estética como pensamento sobre a obra. No lugar dela, o pixador é o novo performer urbano, que sinaliza, batizando com seu nickname ou "nome de guerra", o cenário da desigualdade. O pixador é o encontro da arte com a vida que dá ganho de causa ao vão que há entre elas.
\end{abstract}

Frente ao discurso estético no qual a sociedade encontra-se inserida, os grafismos urbanos apresentam-se como um discurso contra-estético, num lugar e em um tempo onde predomina a estética da fachada, ou como aborda Tiburi (2013), a "estética do muro branco", em que a autora faz uma interessante analogia, aduzindo que no cenário contemporâneo

Ser atingido na fachada - seja a imagem pessoal, seja a imagem do muro branco - é ser atingido num direito. A fachada é narcísica como um rosto, como a imagem que alguém tem de si. O representante original da ideologia do muro branco (e seus apêndices: esposa e filhos) que se irrita quando é atingido na fachada. (2013, p.42).

Portanto, a prática do pixo e do graffiti apresenta-se como contra-espaço, um palco que possibilita o reclame pelo direito à cidade, pelo direito de existência, pela apropriação de um espaço. Essa ocupação urbana, "para os pichadores é a defesa de sua fala indomável e soberana, contra-estética e contra-política” (TIBURI, 2013, p. 45). 
2. A DiCOTOMIA POSTA NA CIDADE DE SANTA MARIA: DIREITO A PROPRIEDADE $X$ DIREITO A EXPRESSÃO DE MANIFESTAÇÃO CULTURAL

Oportuno neste ponto trazer um olhar etnográfico ${ }^{4}$ da temática. As antropólogas Ana Luiza Carvalho da Rocha e Cornelia Eckert (2003), publicaram um artigo no qual abordaram a importância da "etnografia de rua". Nesse trabalho, trouxeram à baila aspectos que demonstram que tal etnografia propõe ao antropólogo um desafio, que é o de desbravar as cidades, provando de diversas experiências, inclusive vivenciando as cores da cidade.

Viver as cores da cidade pode ser um convite a buscar essa reviravolta na estética urbana, propiciada pela prática do pixo e do graffiti.

Os estudos da antropologia, no que tange às cidades, é recente. Ademais, o propósito desses estudos é a análise das cidades, perpassando, essencialmente, pelas suas dinâmicas. Nesse ponto, o conceito de comunidade aparece de forma oposta ao conceito de sociedade. A primeira é marcada por laços sanguíneos, enquanto a segunda pela troca de equivalentes.

A importância dessa dicotomia encontra respaldo na possibilidade de explicar a dinâmica das cidades a partir da dominação, da invasão, da competição por espaço. Ou seja, neste aspecto, a comunidade é "o resultado das relações simbióticas, ao passo que sociedade depende da comunicação entre seus membros que compartilham atitudes, sentimentos e ideias comuns" (MAGNANI, 1996, p.07). Assim, explica-se a importância de utilizar-se de estudos antropológicos para compreender de forma sistêmica estes fenômenos, que ocorrem nos centros urbanos.

\footnotetext{
4 “A etnografia consiste em descrever práticas e saberes de sujeitos e grupos sociais a partir de técnicas como observação e conversações, desenvolvidas no contexto de uma pesquisa. Interagindo-se com o Outro, olha-se, isto é, "ordena-se o visível, organiza-se a experiência" conforme propõe Régis Debray9 . O etnógrafo descreve, tradicionalmente em diários, relatos ou notas de campo, seus pensamentos ao agir no tempo e espaço histórico do Outro-observado, delineando as formas que revestem a vida coletiva no meio urbano. A etnografia de rua, aqui, é um deslocamento em sua própria cidade, o que significa dizer, dentro de uma proposta benjaminiana, que ela afirma uma preocupação com a pesquisa antropológica a partir do paradigma estético10 na interpretação das figurações da vida social na cidade. Um investimento que contempla uma reciprocidade cognitiva como uma das fontes de investigação, a própria retórica analítica do pesquisador em seu diálogo com o seu objeto de pesquisa, a cidade e seus habitantes. Uma vez que tal retórica é portadora de tensões entre uma tradição de pensamento científico e as representações coletivas próprias que a cidade coloca em cena, o pesquisador constrói o seu conhecimento da vida urbana na e pela imagem que ele compartilha, ou não, com os indivíduos e/ou grupos sociais por ele investigados." (ROCHA; ECKERT, 2003, p.03).
} 


\section{OS GRAFISMOS URBANOS COMO MECANISMO DE BUSCA DO DIREITO À CIDADE SUSTENTÁVEL: UMA ANÁLISE SOB A ÓTICA DAS PRÁTICAS SUSCEDIDAS NA CIDADE \\ DE SANTA MARIA - RS}

A antropologia moderna estuda, dentre outros vários grupos ${ }^{5}$, os moradores da periferia, aqueles que pela exclusão, tratada no capítulo anterior, são privados de direitos sociais. Assim, revela-se a importância de estudar estes grupos. Mas antes de adentrar nessa realidade, insta referir que a pretensão do presente trabalho não é esgotar essa análise, uma vez que, por ser uma análise complexa, jamais caberia nas estreitas linhas de um trabalho.

Desse modo, buscar-se-á, de forma incipiente e meramente exemplificativa, trazer a realidade da cidade de Santa Maria, no Rio Grande do Sul, não buscando fazer uma leitura das diversas formas de intervenções gráficas no ambiente urbano, mas, mais do que isso, o objetivo é demostrar o quanto a virada estética é presente no ambiente urbano.

Dentro da cidade, o que se percebe é que o centro é o local que possui mais interferência gráfica. Segundo Magnani (1996), a fragmentação de espaços recebe a denominação de pedaço. Dessa forma, cada pedaço, que pode ser entendido como aquele espaço, que fica entre o privado e o público. Assim, o pedaço é considerado "ao mesmo tempo o resultado de práticas coletivas (entre as quais as de lazer) e condição para o seu exercício e fruição" (MAGNANI, 1996, p.13).

Durante o ano de 2016, a autora percorreu a cidade de Santa Maria, RS, buscando dar cor ao seu trabalho e demonstrando, com imagens, a apropriação urbana que vem ocorrendo. Cumpre aduzir que jamais houve dificuldades na coleta das imagens, pois a cidade, de ponta a ponta, modificou sua estética urbana.

Figura 1- Pixo no Bairro Medianeira, Santa Maria (RS)

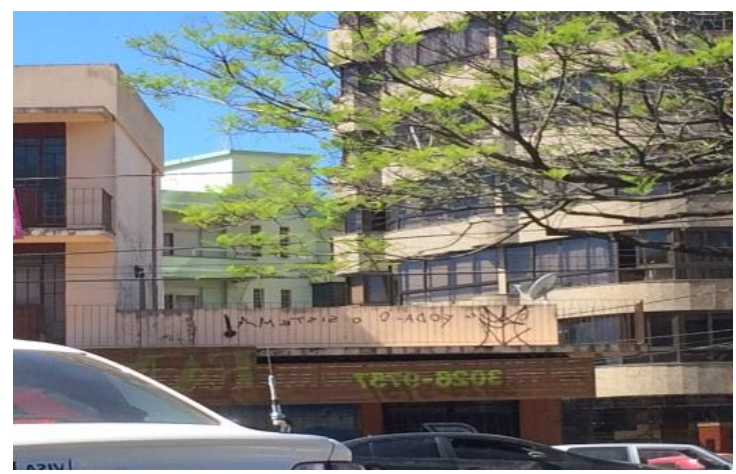

Fonte: autor.

\footnotetext{
5 Assim como religiões populares urbanas, comunidades eclesiais de base, culturas e festas populares, formas de lazer, feminismo, movimento negro, manifestações políticas, entre outros. (MAGNANI, 1996, p.10-1).
}

Rev. de Direito Urbanístico, Cidade e Alteridade | e-ISSN: 2525-989X | Maranhão | v. 3 | n. 2 | p. 104 - 124 | Jul/Dez. 2017. 
Na Figura 1 percebe-se a inserção do texto "foda-se o sistema". Tem-se a inserção de um pixo legível, somado, ao lado direito, de uma tag. Funcionam como marcas de determinados grupos, que com as tags marcam sua passagem na cidade. Há outros exemplos que se enquadram no mesmo estilo acima narrado.

Figura 2 - Pixo na Rua Sarafim Valandro, Santa Maria (RS)

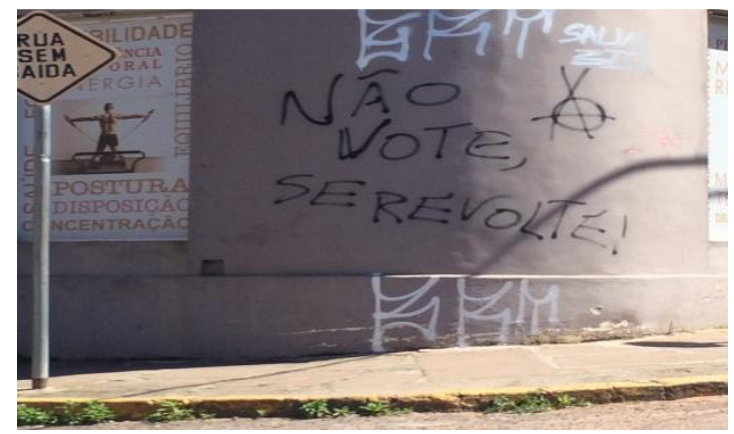

Fonte: autor.

Na Figura 2, na mesma linha da Figura 1, trata o pixo de uma mensagem de cunho político, seguida de uma necessidade de identificação. Ou seja, mesmo que nem para todos a identificação seja clara, para alguns grupos a tag apresenta significado.

Figura 3 - Pixo Rua Serafim Valandro, Santa Maria (RS)

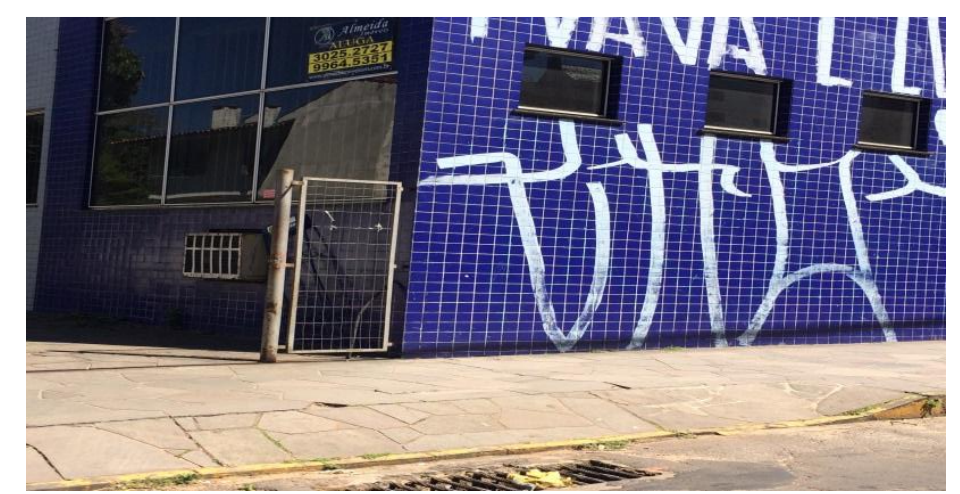

Fonte: autor. 


\section{OS GRAFISMOS URBANOS COMO MECANISMO DE BUSCA DO DIREITO À CIDADE SUSTENTÁVEL: UMA ANÁLISE SOB A ÓTICA DAS PRÁTICAS SUSCEDIDAS NA CIDADE

Figura 4 - Pixo Rua Fernando Ferrari, Santa Maria (RS)

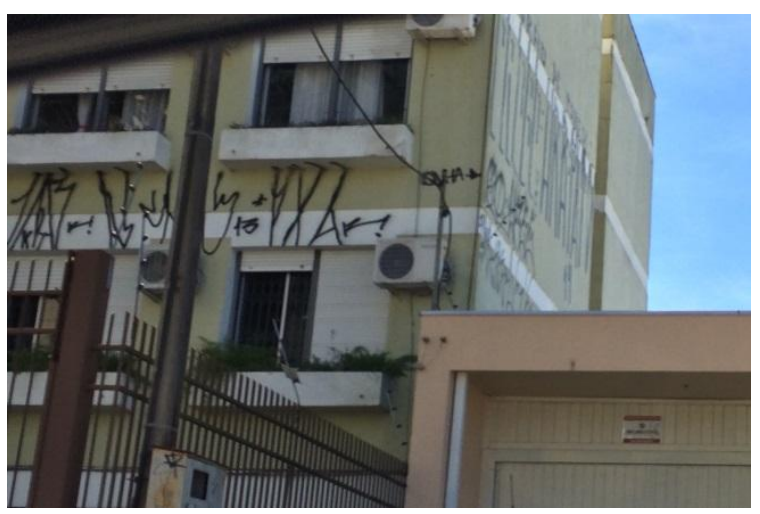

Fonte: autor.

Nas Figuras 3 e 4, o que se vislumbra é a imposição de tags que sequer podem ser traduzidas, mas, embora não possam ser reveladas aos olhos daqueles que desconhecem a cultura dos grafismos urbanos, fato é que estas também revelam mensagens e fazem parte da nova estética urbana.

De outra banda, para além do pixo, que conforme explicitado no segundo capítulo deste trabalho, é aquele que incomoda mais a sociedade no que tange à estética, há também a existência do graffiti, que autorizado ou não, é entendido enquanto arte, seja para fins legais ou ideológicos, como um todo. É necessário, nesse ponto, abrir um espaço para trazer à baila os grafismos urbanos que foram inseridos no local da tragédia a Boate Kiss $^{6}$. Isso porque, de forma controversa, a sociedade apoiou o pixo que foi inserido no local. Obviamente, não se questiona a aprovação da inserção do graffiti, e sim do pixo.

\footnotetext{
6 "O incêndio na boate Kiss foi uma tragédia que matou 242 pessoas e feriu 680 outras numa discoteca da cidade de Santa Maria, no estado brasileiro do Rio Grande do Sul. O incêndio ocorreu na madrugada do dia 27 de janeiro de $\underline{2013}$ e foi causado por um sinalizador disparado no palco em direção ao teto por um integrante da banda que se apresentava no local. A imprudência e as más condições de segurança ocasionaram a morte de mais de duas centenas de pessoas.O sinistro foi considerado a segunda maior tragédia no Brasil em número de vítimas em um incêndio, sendo superado apenas pela tragédia do Gran Circus Norte-Americano, ocorrida em 1961, em Niterói, que vitimou 503 pessoas; e teve características semelhantes às do incêndio ocorrido na Argentina, em 2004, na discoteca República Cromañón. Classificou-se também como a quinta maior tragédia da história do Brasil, a maior do Rio Grande do Sul, a de maior número de mortos nos últimos cinquenta anos no Brasil e o terceiro maior desastre em casas noturnas no mundo. Procedeu-se a uma investigação para a apuração das responsabilidades dos envolvidos, dentre eles os integrantes da banda, os donos da casa noturna e o poder público. O incêndio iniciou um debate no Brasil sobre a segurança e o uso de efeitos pirotécnicos em ambientes fechados com grande quantidade de pessoas. A responsabilidade da fiscalização dos locais também foi debatida na mídia. Houve manifestações nas imprensas nacional e mundial, que variaram de mensagens de solidariedade a críticas sobre as condições das boates no país e a omissão das autoridades. $\mathrm{O}$ inquérito policial apontou muitos responsáveis pelo acidente, mas poucos foram denunciados pelo Ministério

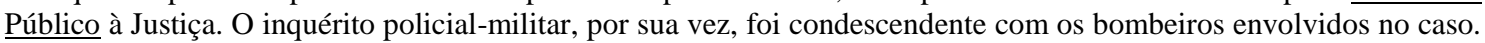
A Justiça instaurou um processo e começou a ouvir depoimentos como preparação para o julgamento, porém os sobreviventes e parentes dos mortos receavam que a impunidade fosse a tônica do evento criminoso. De fato, os servidores civis e militares, bem como as autoridades públicas, corriam pouco risco de sofrerem punições" (WIKIPEDIA, xxxxx).
} 
Vários episódios de pixo no prédio da boate foram registrados ${ }^{7}$, mas tudo iniciou com o a inserção gráfica de "Justiça a todos", isso porque, na hora em que o jovem pichava o prédio, os policiais militares se dirigiram ao local para efetivar a prisão do pixador, momento em que ouviram críticas dos que ali estavam, que clamavam pela prisão dos “culpados" pela tragédia. Senão vejamos a entrevista do pichador:

- Logo depois da tragédia da boate Kiss, teve a pichação do "Justiça a todos", que circulou bastante e pareceu ter apoio da população. Tu acha que esse apoio foi esquecido agora?

Lá, as pessoas apoiaram por causa do momento, todo mundo sofrendo. Eu fiquei bem emocionado também, estava de cara com toda a situação, não dava para ficar quieto. Tinha que subir no bagulho, botei a cara mesmo. Subi e os caras queriam que eu descesse, eles iam me prender, e aí as pessoas começaram a gritar 'não, prende os culpados'. Aí, vi que iam me prender e saí por trás.

- Foi uma situação atípica?

Sei lá, eles aceitaram na hora porque acho que aquilo ali serviu meio que como um consolo, todo mundo queria dizer mas ninguém falava. Tanto que o bagulho tá lá até hoje. E agora, quem é que vai proteger o pixador? Tu acha que os policiais vão falar 'parabéns pelo que tu fez lá', ou tu acha que vão ir lá na frente da delegacia pedirem para me soltarem, para não me prenderem? Jura! Foi só de momento mesmo, o pessoal não tá nem aí, já até esqueceram... (REVISTA O VIÉS, 2013, s.p).

Abaixo segue o primeiro pixo, acima referido, e posteriormente a ilustração atual da situação a fachada no ano de 2016 :

Figura 5 - Primeiro Pixo na Boate Kiss, Santa Maria (RS), 2013

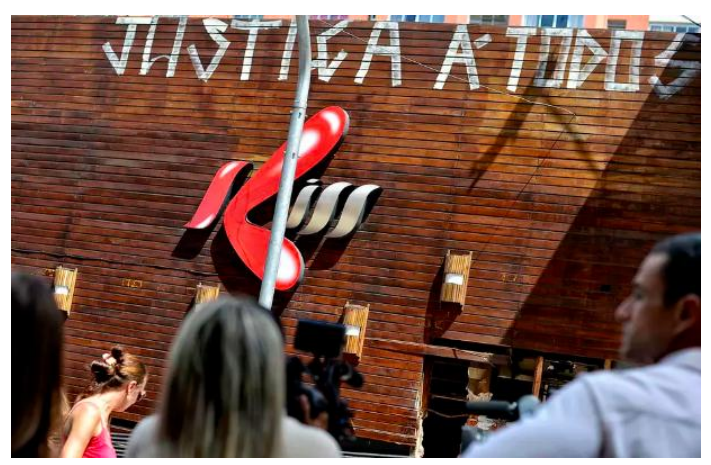

Fonte: Terra. Disponível em: <https://noticias.terra.com.br/brasil/cidades/tragedia-emsanta-maria/rio-menos-de-5-das-casas-noturnas-vistoriadas-estao-

\footnotetext{
${ }^{7}$ Vide o site: http://subsoloart.com/blog/2014/01/boate-kiss-X-impunidade-a-revolta-e-expressao-do-povo/
} 
regulares,97d95b9bc669c310VgnVCM20000099cceb0aRCRD.html>. Acesso em: 02 out. 2016.

Figura 6 - Pixo Boate Kiss, Santa Maria (RS), 2016

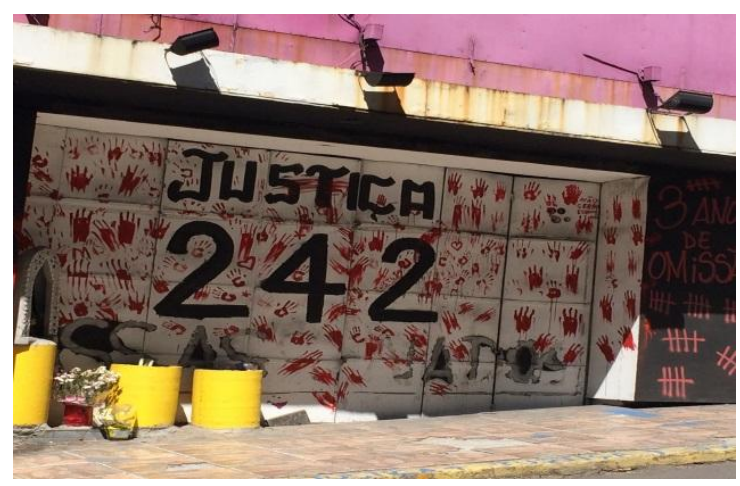

Assim, o que se percebe é que o pixo da Boate Kiss apenas não chocou a sociedade, pois gritava também o desejo e angústias sociais do momento, ou seja, quando o grito proposto pelo pixo agrada a sociedade ele recebe apoio. Afinal, não há como negar que a mensagem passada pelos grafismos urbanos é forte e atinge seus propósitos. Desse modo, questões estéticas são deixadas de lado e o que permanece é o propósito inicial dos grafismos: dar voz a quem não está sendo ouvido!

\section{SUSTENTABILIDADE: UM CONCEITO MULTIFACETADO E (IN)DISSOCIADO DO DIREITO À CIDADE}

Antes de falar na possibilidade de existência de uma cidade sustentável, ainda mais na busca por ela, é necessário abordar o conceito de sustentabilidade, o que implica adentrar em um conceito nada solidificado pela doutrina moderna, uma vez que o cenário de desenvolvimento atual foi construído a partir de um modelo que prioriza valores econômicos.

Cabe aduzir que o termo sustentável foi, primordialmente, debatido na década de 70, pela comunidade científica, utilizado para designar a possibilidade de um ecossistema 
não perder sua resiliência; sendo, após este momento, utilizado nos anos 80, para qualificar o termo desenvolvimento (VEIGA, 2006, p.12).

Nesse sentido, Juarez Freitas define a sustentabilidade como um princípio, que determina a responsabilidade do Estado, em conjunto com a sociedade pela concretização solidária do desenvolvimento material e imaterial, ambientalmente limpo, inovador, no intuito de assegurar o direito ao bem-estar (FREITAS, 2012).

Há que se ressaltar que foi no ano de 1988, com a publicação do relatório Nosso Futuro Comum, conhecido como Relatório Brundtland, pela Comissão Mundial sobre Meio Ambiente e Desenvolvimento da ONU, que o conceito mais simplista e difundido de sustentabilidade se tornou conhecido, como sendo "aquele que atende às necessidades do presente sem comprometer a possibilidade de as gerações futuras atenderem às suas necessidades" (ONU, 1988).

Contudo, a ideia de sustentabilidade ligada estritamente com relação ao meio ambiente resta ultrapassada. Dessa forma, portanto, sofreu diversas críticas de autores que defendem a ideia de que a sustentabilidade de possuir um viés multidimensional. Assim, o conceito de sustentabilidade deve ser concebido como sendo um conceito multifacetado, contudo, em relação ao número de dimensões e quais seriam elas os doutrinadores não são uníssonos.

A título de exemplo, Juarez de Freitas (2012, p.56) apresenta cinco dimensões, quais sejam: ambiental, econômica, social, ética e jurídico-política. Enquanto que José Eli da Veiga (2006, p.12) refere que o Relatório Brundtland determina que a sustentabilidade permeia as sete dimensões da vida, a saber: econômica, social, territorial, científica e tecnológica, política e cultural.

Ignacy Sachs (1994, p.37), chegou a referir que a sustentabilidade apresentava cinco dimensões, quais sejam: sustentabilidade social; sustentabilidade econômica; sustentabilidade ecológica; sustentabilidade espacial e sustentabilidade cultural. E posteriormente, o mesmo autor, em 2002, passou a referir que a sustentabilidade possui oito dimensões.

Optou-se, neste estudo, por abordar as dimensões trazidas por Freitas (2012, p. 58). Assim sendo, a dimensão social da sustentabilidade é de suma relevância para os construtos deste trabalho, posto que sua aplicação remete à negação de um modelo de desenvolvimento excludente e injusto. E é nesta dimensão que ganham espaço os direitos fundamentais sociais. 


\section{OS GRAFISMOS URBANOS COMO MECANISMO DE BUSCA DO DIREITO À CIDADE SUSTENTÁVEL: UMA ANÁLISE SOB A ÓTICA DAS PRÁTICAS SUSCEDIDAS NA CIDADE \\ DE SANTA MARIA - RS}

Já a dimensão ética da sustentabilidade é conceituada pelo autor com um viés atrelado ao "sentido de que todos os seres possuem uma ligação intersubjetiva e natural, donde segue a empática solidariedade como dever universalizável de deixar o legado positivo na face da terra" (FREITAS, 2012, p.60). Assim, pode-se entender que a dimensão ética é intimamente ligada ao conceito de cooperação e de busca por um modelo de ética universal, que reconheça a dignidade intrínseca dos seres vivos, "acima dos formalismos abstratos e dos famigerados transcendentalismos vazios" (FREITAS, 2012, p.63).

A dimensão ambiental representa o conceito mais difundido, uma vez que remete à abordagem trazida em 1988 no Relatório de Brundtland, ou seja, aborda o direito das gerações atuais, sem prejuízo das futuras, ao ambiente limpo. Tal conceito perdeu força quando analisado de forma isolada pois tornou-se insuficiente, contudo, é uma peça importante no quebra-cabeça da sustentabilidade (FREITAS, 2012).

A dimensão econômica, segundo Freitas (2012, p. 66) "não pode ser separada da medição de consequências de longo prazo. Nessa perspectiva, o consumo e a produção precisam ser reestruturados completamente". Com isso, o autor defende a ideia de que a natureza não pode ser vista como um bem disponível. Portanto, o Estado deve agir e insurgir-se no sentido de coibir sua capitalização que ignora a complexidade do mundo natural.

Por sua vez, a dimensão jurídico-política pode ser representada pela ideia de direito ao futuro e, portanto, apresenta-se como dever constitucional a proteção da liberdade de cada cidadão (FREITAS, 2012, p.68).

Ao fim e ao cabo, o autor defende a importância do entrelaçamento destas dimensões, tendo em vista que constituem mutuamente uma dialética da sustentabilidade e que não pode ser rompida, sob pena de irremediável prejuízo e que se tratam de componentes essenciais à modelagem do desenvolvimento (FREITAS, 2012, p.71).

Diante disso, resta evidente que a sustentabilidade apenas possui concretude quando referida em consonância a um lugar e a um tempo específicos, ao sujeito do discurso, sobretudo, aos atores e agente cuja razão social seria a implementação de um modelo de desenvolvimento sustentável (MANTOVELI JÚNIR, 2012, p.71).

O desenvolvimento sustentável, da mesma forma, só faz sentido quando observado a partir da ótica multidimensional, pois configura hodiernamente um desafio 
que pressupõe a consideração das diversas dimensões culturais e éticas no processo de tomada de decisão, e as ações coletivas e altruisticamente motivadas, de modo a retirar toda a carga devastadora das decisões pautadas na maximização de interesses individuais de agentes econômicos específicos (ROMEIRO, 2010, p.28).

Costuma-se ligar o conceito de desenvolvimento ao desenvolvimento econômico. Contudo, autores como Amartya Sen apresentam uma nova perspectiva de desenvolvimento, desatrelada destas variáveis, consistindo em uma concepção que considera a liberdade como meio e fim do desenvolvimento. Nesse sentido, o autor considera que

\footnotetext{
Os fins e os meios do desenvolvimento requerem análise e exame minuciosos para uma compreensão mais plena do processo de desenvolvimento; é sem dúvida inadequado adotar como nosso objetivo básico apenas a maximização da rena ou da riqueza, que é, como observou Aristóteles, "meramente útil e em proveito de alguma outra coisa". Pela mesma razão, o crescimento econômico não pode sensatamente ser considerado um fim em si mesmo. $O$ desenvolvimento tem de estar relacionado sobretudo com a melhora da vida que levamos e das liberdades que desfrutamos (SEN, 2000, p.29).
}

A privação de liberdades, que é verificada atualmente no contexto contemporâneo, consiste notadamente na carência de oportunidades de acesso à saúde, educação, emprego remunerado, segurança social, serviços de saúde, saneamento básico e água tratada. Nessa senda, o desenvolvimento pode ser visto como um processo de emancipação das liberdades reais que as pessoas desfrutam.

A partir dessa perspectiva, o desenvolvimento para ser efetivo carece da remoção das principais fontes de privação de liberdade, quais sejam: pobreza e tirania, carência de oportunidade econômica e destruição social sistemática, negligência dos serviços públicos e intolerância ou interferência excessiva dos Estados.

Na mesma linha de raciocínio, Juarez Freitas (2012) faz referência à inconsistência do conceito de desenvolvimento sustentável, referindo acerca do fato que as crises atuais se interagem entre si, compondo uma crise sistêmica:

Trata-se, sem dúvida, de crise superlativa e complexa. Crise do aquecimento global, do ar irrespirável, da desigualdade brutal de renda, da favelização incontida da tributação regressiva e indireta, da escassez visível de democracia participativa, da carência flagrante de qualidade da educação (inclusive ambiental), das doenças facilmente evitáveis, da falta de paternidade e maternidade conscientes, do stress hídrico global, da regulação inerte, tardia ou impotente, do desaparecimento de espécies, da queimada criminosa, da produção de resíduos que cresce em ritmo superior ao da população e da impressionante imobilidade urbana(FREITAS, 2012, p.25-26). 


\section{OS GRAFISMOS URBANOS COMO MECANISMO DE BUSCA DO DIREITO À CIDADE SUSTENTÁVEL: UMA ANÁLISE SOB A ÓTICA DAS PRÁTICAS SUSCEDIDAS NA CIDADE \\ DE SANTA MARIA - RS}

No cenário contemporâneo, não há mais espaço para pensar no conceito de desenvolvimento sustentável e no conceito de sustentabilidade como um padrão ligado a questões econômicas e ambientais tão somente. Portanto, suas multidimensões devem ser consideradas de forma conjunta.

Ao fim e ao cabo, a partir da análise multidimensional da sustentabilidade, notadamente atendo-se à sustentabilidade social, pode-se concluir que não pode haver ou ser permitida - a existência de uma "discriminação negativa" (FREITAS, 2012, p.58). Pois, segundo a análise de Juarez Freitas, as únicas distinções possíveis dão-se no sentido de incluir minorias, e não o contrário. O autor é cirúrgico ao concluir sua abordagem no seguinte sentido:

Consigne-se que, comprovadamente, as sociedades equitativas, não as mais ricas e assim éticas, são aquelas percebidas como as mais aptas a produzir bemestar. Em suma, a sustentabilidade na sua dimensão social, reclama:

a) o incremento da equidade intra e intergeracional;

b)condições propícias ao florescimento virtuoso das potencialidades humanas, com educação de qualidade para o convívio; $\mathrm{e}$

c) por último, mas não menos importante, o engajamento na causa do desenvolvimento que perdura e faz a sociedade mais apta a sobreviver, a longo prazo, com dignidade e respeito à dignidade dos demais seres vivos. (FREITAS, 2012, p.58).

Ou seja, pode-se falar na busca do direito ao acesso à cidade sustentável. Este conceito, ou melhor, a preocupação com as cidades sustentáveis não data de hoje, uma vez que, desde a Conferência da ONU sobre Desenvolvimento e Meio Ambiente, verificou-se um debate voltado também para políticas urbanas (ACSELRAD, 2001, p.37).

Assim, pensando na multidimensão social da sustentabilidade um dos pontos que devem ser buscados no ambiente urbano é a qualidade de vida. Nesse sentido, oportuno trazer o que aduziu Henri Acselrad (2001, p.43):

Tal representação da cidadania urbana tende a espraiar-se para o conjunto das políticas urbanas, justificando estruturas que favorecem o desenvolvimento do diálogo e da negociação, bem como a realização de pactos de atribuição de sentido à duração das cidades, não só em sua materialidade, mas enquanto institucionalidade sociopolítica.

$\mathrm{O}$ autor se refere a uma necessidade de manutenção da institucionalidade sociopolítica. Ocorre que esta só pode ser percebida a partir da preservação de identidades, de culturas diversas, de um ambiente que comtemple a todos os usuários das cidades. 
Para a discussão que traz por pano de fundo a virada estética da cidade com a inserção de grafismos urbanos é necessário pensar na ótica social que nasce detrás da existência das manifestações culturais, por mais que hajam contrapontos a serem discutidos na esfera da propriedade privada, que indubitavelmente é atacada. Nesse sentido, Ribeiro (2005, p.60) questiona se pode ou não uma cidade ser sustentável:

Ora, essa pergunta só faria sentido se a cidade fosse um organismo vivo,
autônomo, dotado de desejo e de capacidade de reprodução. Isso não ocorre.
A cidade é, antes de mais nada, realização humana, obra edificada ao longo de
muitos séculos. A concentração dos seres humanos em cidades é que deve ser
analisada sobre a ótica da sustentabilidade. O que deve ser sustentável não é a
cidade, mas o estilo de vida urbano, que tem nas cidades mais uma forma de
manifestação.

E como fazer então que o estilo de vida urbano seja sustentável? Segundo Gregori e Loureiro (2013), isso somente é possível se forem propostas e realizadas atitudes concretas dos municípios, "tanto para fatores diretos de sustentabilidade como para uma paulatina educação ambiental dos cidadãos" (GREGORI; LOUREIRO, 2013, p.465).

A cidade não nasce sustentável. E a busca pela cidade sustentável implica observar todas as suas multidimensões, garantindo direitos sociais a todos os usuários de ambiente urbano, que devem ter garantido muito mais do que o acesso à cidade, mas sim a tudo que ela oferece, em sentido amplo. Afinal, os espaços devem ser mais do que públicos, devem ser populares, com respeito a toda a diversidade que é propiciada e vislumbrada em um mundo globalizado.

Ao fim e ao cabo, parece interessante encerrar esse trabalho com uma contribuição de Flávio Ahmed (2009) que, em outro contexto, falando de cidades sustentáveis, assim refere: "a cidade é um texto, mas deve ser vista como obra a ser escrita pelos seus anseios e vocações culturais que cabem ser estimuladas" (AHMED, 2009, p.21). Dessa forma, há que se deixar que todos os atores sociais possam escrever na sua cidade.

\section{CONCLUSÃO}

Sem a intenção de esgotar a temática tratada, o presente estudo buscou descortinar em que medida os grafismos urbanos podem ser compreendidos como uma forma legítima de busca pelo acesso à cidade.

Por fim, com o exemplo trazido das inserções na cidade de Santa Maria, RS, foi possível perceber uma série de pontos, denotando que não há dúvidas de que os grafismos 


\section{OS GRAFISMOS URBANOS COMO MECANISMO DE BUSCA DO DIREITO À CIDADE SUSTENTÁVEL: UMA ANÁLISE SOB A ÓTICA DAS PRÁTICAS SUSCEDIDAS NA CIDADE \\ DE SANTA MARIA - RS}

estão presentes em todo o espaço urbano, pois não foram percebidas dificuldades para encontrar todos os tipos de grafismos na cidade, principalmente no centro: vislumbrouse a inserção de grafittis, pixos retos, tags, protestos políticos e outros. Afinal, é inegável que a estética da cidade mudou.

Concluiu-se que a regra é a rejeição social no que tange a inserção dos grafismos urbanos, mas, ao analisar especificamente os pixos inseridos na Boate Kiss, percebeu-se que este teve apoio social. Diante disso, notou-se é que tal inserção gráfica apenas não chocou a sociedade, pois gritava também o desejo e angústias sociais do momento, ou seja, quando o grito proposto pelo pixo agrada a sociedade ele recebe apoio. Afinal, não há como negar que a mensagem passada pelos grafismos urbanos é forte e atinge seus propósitos. Desse modo, questões estéticas são deixadas de lado e o que permanece é o propósito inicial dos grafismos: dar voz a quem não está sendo ouvido.

A cidade não nasce sustentável. E a busca pela cidade sustentável implica observar todas as suas multidimensões, garantindo direitos sociais a todos os usuários de ambiente urbano, que devem ter garantido muito mais do que o acesso à cidade, mas sim a tudo que ela oferece, em sentido amplo.

Assim, o que se percebe é que os espaços devem ser mais do que públicos, devem ser populares, com respeito a toda a diversidade que é propiciada e vislumbrada em um mundo globalizado e plural.

\section{REFERÊNCIAS}

AHMED, Flávio. A cultura e o lazer na perspectiva da sustentabilidade das cidades. In: AHMED, Flávio; COUTINHO, Ronaldo. (Orgs.) Cidades Sustentáveis no Brasil e sua tutela jurídica. Rio de Janeiro: Editora Lumen Juris, 2009.

ARCE, José Manuel Velenzuela. Vida da barro duro: cultura popular juvenil e grafite. Tradução de Heloísa Rocha. Rio de Janeiro: UFRJ, 1999.

CANCLINI, Néstor García. Diferentes, desiguais, desconectados: mapas da interculturalidade. Tradução: Luis Sérgio Henriques. 3.ed. Rio de Janeiro: Editora UFRJ, 2009.

CANCLINI, Néstor García. Políticas Culturales em America Latina. México: Editora Griialbo. 1987. p. 13-61.

CUNHA FILHO, Francisco Humberto. Tese. Cultura e Democracia na Constituição Federal de 1988: Representação de Interesses e a sua Aplicação ao Programa Nacional

Rev. de Direito Urbanístico, Cidade e Alteridade | e-ISSN: 2525-989X | Maranhão | v. 3 | n. 2 | p. 104 - 124 | Jul/Dez. 2017. 
de Apoio à Cultura. 2004. 234 p. Tese (Doutorado em Direito), Faculdade de Direito, Universidade Federal de Pernambuco, Recife, 2004.

DEBORD, Guy. A sociedade do espetáculo. Tradução: Estela dos Santos Abreu. Rio de Janeiro: Contraponto, 1997.

GITAHY, Celso. O que é graffiti. São Paulo: 1999.

FREITAS, Juarez. Sustentabilidade: Direito ao Futuro. Belo Horizonte: Fórum, 2012.

GREGORI, Isabel Christine de; LOUREIRO, Monica Michelotti. Como construir cidades sustentáveis? I Congresso Internacional de Direito Ambiental e Ecologia Política III Seminário de Ecologia Política e Direito na América Latina. 2013. p.458-469. Disponível em:

<https://periodicos.ufsm.br/revistadireito/article/view/8348/5030\#.V-R6hJMrI9c>. Acesso em: 07 set. 2016.

LIPOVETSKY, Gilles; SERROY, Jean. A cultura-mundo: resposta a uma sociedade desorientada. Tradução: Maria Lúcia Machado. São Paulo: Companhia das Letras, 2011.

MAGNANI, José Guilherme Cantor. Quando o campo é a cidade: fazendo antropologia na metrópole. In: Magnani, José Guilherme C. \& Torres, Lilian de Lucca (Orgs.) Na Metrópole: Textos de Antropologia Urbana. São Paulo: EDUSP, 1996.

MANTOVANELI JÚNIOR, Oklinger. A sustentabilidade como projeto para a cidadania planetária. In: PHILIPPI JÚNIOR, Arlindo; SAMPAIO, Carlos Alberto Cioce; FERNANDES, Valdir. Gestão de natureza pública e sustentabilidade. Barueri: Manole, 2012.

ORGANIZAÇÃO DAS NAÇÕES UNIDAS PARA A EDUCAÇÃO, A CIÊNCIA E A CULTURA - UNESCO. Convenção para a Proteção do Patrimônio Mundial, Cultural e Mundial de 1972. Disponível em:

<http://whc.unesco.org/archive/convention-pt.pdf>. Acesso em: 25 jan. 2016.

RINK, Anita. Graffiti: Intervação Urbana e Arte. Apropriação dos Espaços dos espaços urbanos com arte e sensibilidade. Curitiba: Appris, 2013.

ROMEIRO, Ademar Ribeiro. Economia ou economia política da sustentabilidade. In. Peter May (org.) Economia do meio ambiente: teoria e prática. 2 ed. Rio de Janeiro: Elsevier, 2010.

SACHS, Ignacy. Estratégias de transição para o século XXI. In: BURSZTYN, Marcel (org.). Para pensar o desenvolvimento sustentável. São Paulo: Brasiliense, 1994.

SANTOS, José Luiz dos. O Que é Cultura. São Paulo: Editora Brasiliense, 1986.

SEN, Amartya. Desenvolvimento como Liberdade. Tradução Laura Teixeira Mota. São Paulo: Companhia das Letras, 2000. 
TIBURI, Marcia. Direito Visual à Cidade: a estética da Pixação e o caso de São Paulo. Revista Ensaios. São Paulo. 2013. p. 39-53. Disponível em: $<$ http://www.redobra.ufba.br/wpcontent/uploads/2013/12/redobra12_EN6_marcia.pdf>. Acesso em: 16 nov. 2015.

VEIGA, José Eli da. Meio ambiente e desenvolvimento. São Paulo: Senac São Paulo. 2006. 